\section{Guide for Authors}

The American Journal of Alternative Agriculture (AJAA) publishes original research on biological, physical, or social science aspects of alternative agriculture. We particularly welcome multidisciplinary studies, but papers from a specific discipline also are invited. However, since AJAA readership is much broader than for a singlediscipline journal, highly specialized terminology should be explained or avoided. The significance of a statement, or the reasoning behind a conclusion, may have to be spelled out more than in a more specialized journal. See Vol. 5, No. 1, pp $2 \& 3$, for an explanation of the various categories of articles.

\section{Units}

Research papers should use the International (SI, or metric) system throughout. Occasional use of common unit equivalents in parentheses is permitted.

\section{Title page}

The title page should give the following information (all flush left): 1) title of the paper; 2) names of the authors; 3 ) affiliation and office address of authors, and 4) disclaimers and publication number, if any. See examples in this issue of AJAA.

\section{Abstract}

The abstract should be 200 to 400 words suitable for readers from a broad range of disciplines. It should avoid highly-specialized terminology that might be appropriate for a single-discipline journal. Take particular care that the significance of the work is made clear, even to readers from a different field.

\section{Key Words}

Provide subject matter key words suitable for use in scientific indexing.

\section{Reference List}

When citing material that has been covered in more than one format, such as the typescript of a conference presentation and a journal article, preference should be given to the version that is most readily available, and that is likely to remain so. Generally this means standard publication channels, such as books, journals, and regular government report series. Unpublished or informally-published material should be cited only when no alternative form exists.

References should be listed in alphabetical order by author's name, and by year for a particular author (with letters after the year if needed). If a sole author is also the lead author of papers with multiple authors, use the following order: single author (by year); two authors (alphabetically by second author's name); three or more authors (by year). Repeat the author's name for each reference. Give the names of all authors in the reference; never use "et al."

Use full names of journals, institutions, conferences, etc., except for extremely familiar abbreviations like "Dept." Remember that an abbreviation familiar to you may not be familiar to readers outside your field. If in doubt, write it out.

The reference list uses no quotation marks, italics, boldface, or underlining. Only the names of books and periodicals are in initial capitals. Names of papers, book chapters, pamphlets, and bulletins are not capitalized.

\section{Citing References}

Cite references in the text by last name and year, with chapter or page numbers if the reference is a book or lengthy report. For two authors, give both names. Do not use "et al." unless there are at least three authors.

\section{Footnotes}

AJAA does not use bibliographic or substantive footnotes. All bibliographic references should be at the end of the text. Instead of substantive footnotes, include the material in the main text or consider eliminating it.

\section{Manuscript Preparation}

The entire manuscript, including abstract and references, should be typed on one side of standard-size paper, double spaced, with margins of at least one inch all around. Starting with the title page, label all pages in the upper righthand corner with the lead author's last name and the page number. Do not use hyphens unless the hyphen is part of the word.

Tables should fit on one page, be numbered consecutively with Arabic numerals, and be on a separate sheet. Every figure and table should be mentioned at least once in the text.

A detailed guide to formatting is available from the editor (address below).

\section{Submission of Manuscripts}

Submit four high-quality copies to Dr. Robert I. Papendick, Editor, American Journal of Alternative Agriculture, Department of Crop \& Soil Science, 253 Johnson Hall, Washington State University, Pullman, WA 99164-6420. The cover letter should state that the manuscript is an original contribution that has not been published elsewhere in substantially the same form, that it is not currently under consideration elsewhere, and that permission has been obtained for any copyrighted material used. 


\section{How you can help support the scientific and educational needs of a sustainable agricultural system}

A growing number of Americans have become concerned about the long-term sustainability of our food production system. Farmers and agricultural scientists are among those raising questions about the growing dependence of modern farming on nonrenewable resources, the depletion of our resource base through soil erosion. and heavy reliance on chemical fertilizers and pesticides. Continued heavy reliance on farm chemicals is questioned because they have become an expensive production input. Their widespread use also raises questions about human and animal health, food quality and safety. environmental quality. and the continued demise of family farms and rural communities.

Alternative farming methods address these economic and environmental challenges. Alternative production systems point the way toward more profits. more individual choice. enhanced environmental quality, and long-term sustainability for our food system. More must be done to develop effective ways to make sure research. education. and information sources are readily available to farmers who want to adopt these techniques.

The Henry A. Wallace Institute for Alternative Agriculture needs your help in meeting this challenge. We are a nonprofit tax-exempt research and education organization established in 1983 to encourage and facilitate the adoption of low cost, resource conserving. and environmentally sound farming methods. We work directly with government agencies. colleges and universities, producer groups. and other institutions that provide research, education and information services to farmers.

The Wallace Institute also provides these services:

- A resource to lawmakers and others who influence agricultural research, education. and information policy.

- A voice for alternative agriculture in Washington

- A sponsor of research and education outreach programs

- A national clearinghouse for information on alternative agriculture

- A publisher of reliable scientific information on agricultural sustainability.

If you're interested in helping us, please contact the Henry A. Wallace Institute for Alternative Agriculture, 9200 Edmonston Road, Suite 117, Greenbelt, Maryland 20770-1551. Telephone: 301-441-8777; E-mail: hawiaa@access.digex.net; Web site: www.hawiaa.org

HENRY A. WALLACE INSTITUTE

FOR ALTERNATIVE AGRICULTURE 